\title{
perifèria
}

Número 20 (1), junio 2015

http://revistes.uab.cat/periferia

\section{ONG, crisis económica e ideología. Aproximación a los efectos de los "recortes" a través del estudio de caso de la ONG AlterNativa. Intercanvi amb els Pobles Indígenes}

Esther Oliver Grasiot- Universitat Autònoma de Barcelona ${ }^{1}$

\section{DOI: http://dx.doi.org/10.5565/rev/periferia.449 \\ Resumen}

La disminución de presupuestos decretada por la Generalitat de Catalunya en el año 2009, en el marco de la recesión económica, tuvo un claro efecto -sobre todo en comparación con otras áreas-, en la política de cooperación del gobierno catalán. Este trabajo es el resultado de una investigación que tiene como objetivo explicar cómo las ONG de cooperación al desarrollo que fueron financiadas principalmente por la Agencia Catalana de Cooperación al Desarrollo afrontan su continuidad debido a la falta de recursos económicos dada la drástica reducción de los presupuestos de la Generalitat, y a la vez identificar si la disminución de financiamiento ha condicionado la relación entre la ONG y su contraparte.

Palabras clave: cooperación, desarrollo, ONG, crisis económica, ideología

\section{Abstract}

The budget cuts decreed by the regional government of Catalonia in 2009, within the frame of the economic crisis, had clear effects on the international cooperation policy of the Catalan government but they did not affect other areas in the same measure. This note comes as a result of a research project with two main goals. The first one is to point that those NGO's who were financed mostly by the ACDD

\footnotetext{
${ }^{1}$ Enviar correspondencia a olivergrasiot@gmail.com
} 


\section{perifèria}

Número 20 (1), junio 2015

http://revistes.uab.cat/periferia

must confront their continuity due to the lack of funding implied in the drastic budget reduction of the Catalan government. The second one is to identify whether the reduction in funds has affected the relationships between the NGO and its counterparty.

Keywords: cooperation, development, NGOs, economic crisis, ideology

\section{Introducción}

La ayuda oficial al Desarrollo, en Catalunya, disminuyó un $70 \%$ en poco más de dos años (Intermón Oxfam 2014). Las consecuencias tuvieron efectos tanto en las organizaciones no gubernamentales catalanas que recibían financiación de la Agencia Catalana de Cooperación al Desarrollo ( $A C C D$ ) como en los países destinatarios, a través de las organizaciones contrapartes.

Este artículo es resultado de una investigación realizada entre el mes de enero y junio de 2014 sobre la ONG AlterNativa. Intercanvi amb els Pobles Indígenes (AlterNativa en lo sucesivo), con sede en Barcelona y su relación con una de sus contrapartes en Guatemala la cual ha contado con financiación de la ACCD durante seis años. Se trata de la asociación Cooperación Indígena para el Desarrollo Integral (COINDI), comprometida con la defensa de los derechos de los pueblos indígenas.

El objetivo principal es explicar cómo las ONG de cooperación al desarrollo que han sido financiadas principalmente con fondos de la ACCD afrontan su continuidad debido a la drástica reducción de los presupuestos de la Generalitat de Catalunya, e identificar si la disminución de financiación condiciona las relaciones entre las ONG y sus contrapartes.

\section{Debates en torno a la cooperación al desarrollo}

Partiendo de la definición que hace Unceta (2013:16) del término cooperación como el "conjunto de instrumentos y políticas puestas en marcha para favorecer los procesos de desarrollo", es necesario en cada momento histórico analizar el 


\section{perifèria}

Número 20 (1), junio 2015

http://revistes.uab.cat/periferia

significado de desarrollo considerando el contexto político y social, ya que esto determinará las políticas, los instrumentos y el discurso en torno a la cooperación internacional al desarrollo.

El concepto de desarrollo surgió a raíz del discurso El estado de la Unión de Truman (1949) al finalizar la Segunda Guerra Mundial (Rist 2002). El paradigma de desarrollo que fue concebido en ese primer momento se refería al crecimiento económico y tecnológico de un país. De acuerdo con la lógica capitalista occidental, se generó toda la maquinaria (instituciones, discursos y prácticas) necesaria para legitimarlo (Rist 2002), por lo que ha sido muy criticado posteriormente por diversos autores como Escobar, 1998; Bretón, 2002; Rist, 2002, entre otros. Cabe decir que el paradigma del desarrollo económico y tecnológico ha ido variando en función del momento histórico y económico y que hoy en día ha sido sustituido por el paradigma del desarrollo humano (DH). Este se caracteriza por tener un enfoque basado en los derechos humanos que tiene presente las capacidades y las opciones de las personas de satisfacer sus necesidades.

En el campo de la antropología se usa "desarrollo" en el sentido de "cooperación internacional al desarrollo". Así, en la antropología del desarrollo existen dos corrientes: la antropología para el desarrollo comprometida con las instituciones de desarrollo y la antropología del desarrollo que aporta una visión crítica (Escobar 1997).

De entre las ideas críticas al desarrollo, cabe destacar la que afirma que el desarrollo es un discurso. Para Rist el desarrollo es una creencia occidental de la modernidad y actúa como un mito desde el que las prácticas se orientan y reorientan con la idea de que es posible lograrlo. Otro autor crítico, Escobar (1998), señala que el desarrollo es una invención etnocéntrica, no es un hecho natural ni inevitable, sino el resultado de procesos históricos.

A día de hoy, el debate sobre la crisis de la cooperación internacional se atribuye a una menor significación de la Ayuda Oficial al Desarrollo (AOD) y el cuestionamiento de su eficacia (Unceta 2013). Para este autor, las causas de esta crisis se deben tanto a las transformaciones producidas por la globalización como a 


\section{perifèria}

Número 20 (1), junio 2015

http://revistes.uab.cat/periferia

la emergencia de un nuevo escenario global en el que hay un distanciamiento entre la lógica del capital privado y la lógica de transferencias públicas, todo ello en un contexto de vigencia del paradigma Norte-Sur. A su vez también es consecuencia de la emergencia de nuevos modelos de desarrollo, de nuevas modalidades de cooperación (Sur-Sur) y de nuevas fuentes de financiación (por ejemplo, China como país donante).

\section{Los agentes de la cooperación: las organizaciones no gubernamentales (ONG)}

Otro de los aspectos clave que se ha discutido dentro de la antropología del desarrollo es el papel de los agentes que participan en la cooperación al desarrollo, y muy concretamente el de las ONG. En un proyecto internacional intervienen, normalmente, una ONG de un país del Norte y otra, que es la contraparte, de un país del Sur².

En relación con las primeras, el estudio La cooperación descentralizada a debate. La eficacia de la ayuda y el post-2015 diferencia entre dos tipos de ONG: las que tienen un perfil de voluntariado y no dependen económicamente de financiadores públicos; y las ONG que se rigen por una lógica del proyecto, tienen una relación con la administración burocratizada, su estructura y volumen de proyectos se ha ampliado y tienen unas estructuras profesionalizadas. Estas ONG dependen principalmente de financiación pública y los requisitos que exige presentarse a las convocatorias de subvenciones públicas, ha provocado un exceso de tecnificación de las ONG. Debido a este motivo las prácticas que llevan a cabo se han definido con el concepto de "proyectorado", haciendo referencia a que el proyecto se ha convertido en el instrumento principal de aplicación de la política de cooperación al desarrollo, el principio y final de la práctica de cooperación (Badia et al. 2013). Para varios autores, como Mosse (2013); Unceta (2013), se da una confrontación entre los discursos y las prácticas de estas ONG, ya que, a pesar de tener un discurso

\footnotetext{
${ }^{2}$ Se diferencia entre Norte y Sur, siguiendo la categoría que utilizan los informantes.
} 


\section{perifèria}

Número 20 (1), junio 2015

http://revistes.uab.cat/periferia

crítico, para mantener su vigencia o supervivencia, están limitadas por los sistemas burocráticos de la cooperación oficial, por lo que pueden llegar a actuar como una empresa convencional.

En relación con las segundas, para Martínez (2010) las ONG del Sur asumen el rol de agentes mediadores, ya que median entre el conocimiento local y el conocimiento externo institucional y son imprescindibles para que las ONG del Norte puedan llevar a cabo los proyectos de cooperación que planifican. También hay que tener presente que las ONG del Sur y/o los beneficiarios de los proyectos aprovechan los recursos del desarrollo para suplir la falta de recursos en la comunidad o para responder a los intereses de ésta (Gray 2002).

\section{La cooperación al desarrollo en Cataluña}

El sector de la cooperación al desarrollo en Cataluña es muy heterogéneo debido al conjunto de actores que participan (administraciones públicas, ONG, sindicatos, fundaciones y empresas, entre otros), a la diversidad interna que configura cada uno de estos actores y a la variedad de actuaciones que llevan a cabo.

El campo de las ONG también es muy heterogéneo. Sin embargo, a partir de sus actuaciones se puede establecer la siguiente tipología: ONG asistencialistas, ONG de ayuda humanitaria y ONG de transformación social ${ }^{3}$.

Las acciones solidarias con los países del Sur han ido variando en función del contexto político y económico. En cuanto al caso catalán, se pueden diferenciar tres momentos clave. Una primera fase entre los años cincuenta y ochenta, donde la mayor parte de las iniciativas solidarias tenía un carácter religioso. Una segunda fase, entre los años ochenta y finales de los noventa, caracterizada por la movilización política y social. Y una última fase, de finales de los noventa hasta hoy en día, donde predomina la gestión y la tecnificación de las tareas.

${ }^{3}$ Entrevista 1: 24/02/2014, Barcelona. 


\section{perifèria}

Número 20 (1), junio 2015

http://revistes.uab.cat/periferia

En este artículo presentaré cómo se ha constituido la última fase de este contexto, ya que ha sido el que ha determinado la situación actual de las ONG en Cataluña.

La Ley catalana de cooperación al desarrollo ${ }^{4}$ establece las bases de la política pública de cooperación al desarrollo y acción humanitaria. Para institucionalizar esta política, la Generalitat, junto con agentes de la cooperación catalana, marca los mecanismos de regulación, normativos y presupuestarios que determinarán el entramado institucional que debe consolidar.

En el año 2003 se creó la Agencia Catalana de Cooperación al Desarrollo (ACCD) ${ }^{5}$. Esta agencia es el organismo de la Generalitat responsable de gestionar y ejecutar la política pública de cooperación al desarrollo y acción humanitaria. Para gestionar esta política, una de las funciones de la ACCD es abrir convocatorias públicas de subvenciones con el objetivo de dotar financiación a proyectos de cooperación al desarrollo y acción humanitaria6. Es importante conocer la evolución de los presupuestos de la partida de cooperación al desarrollo de la Generalitat. El presupuesto en 2007 fue de 67 millones de euros y en 2008 de 82 millones de euros. Sin embargo, alegando la crisis económica, en 2009 se empezó a reducir hasta 49 millones de euros. En 2010 se intentó reducir un 20\% más pero ante la movilización del sector se mantuvo el mismo importe que el año anterior. En 2011 fue de 22,5 millones de euros, en 2012 de 15,2 millones, en 2013 de 11,9 millones, y el 2014 es de 6,23 millones. En definitiva, del 2008 al 2013 la reducción fue del $95 \%{ }^{7}$.

\footnotetext{
${ }^{4}$ Llei 26/2001 de 31 de desembre de cooperació al desenvolupament.

${ }^{5}$ La investigación se centra en el caso de la ACCD porque ha sido el financiador de la Generalitat que ha destinado más recursos económicos a la cooperación y al mismo tiempo porque es el actor que los ha reducido más drásticamente.

${ }^{6}$ La investigación analiza el caso de las convocatorias públicas de subvenciones que se destinan a ONG, ya que estos agentes han sido los principales actores de la gestión de los fondos de cooperación. Entre 2006 y 2010 las ONG han gestionado una media de un 60\% del total de los fondos de cooperación (FCONGD 2013).
}

7 El País, ed. (2013). 


\section{perifèria}

Número 20 (1), junio 2015

http://revistes.uab.cat/periferia

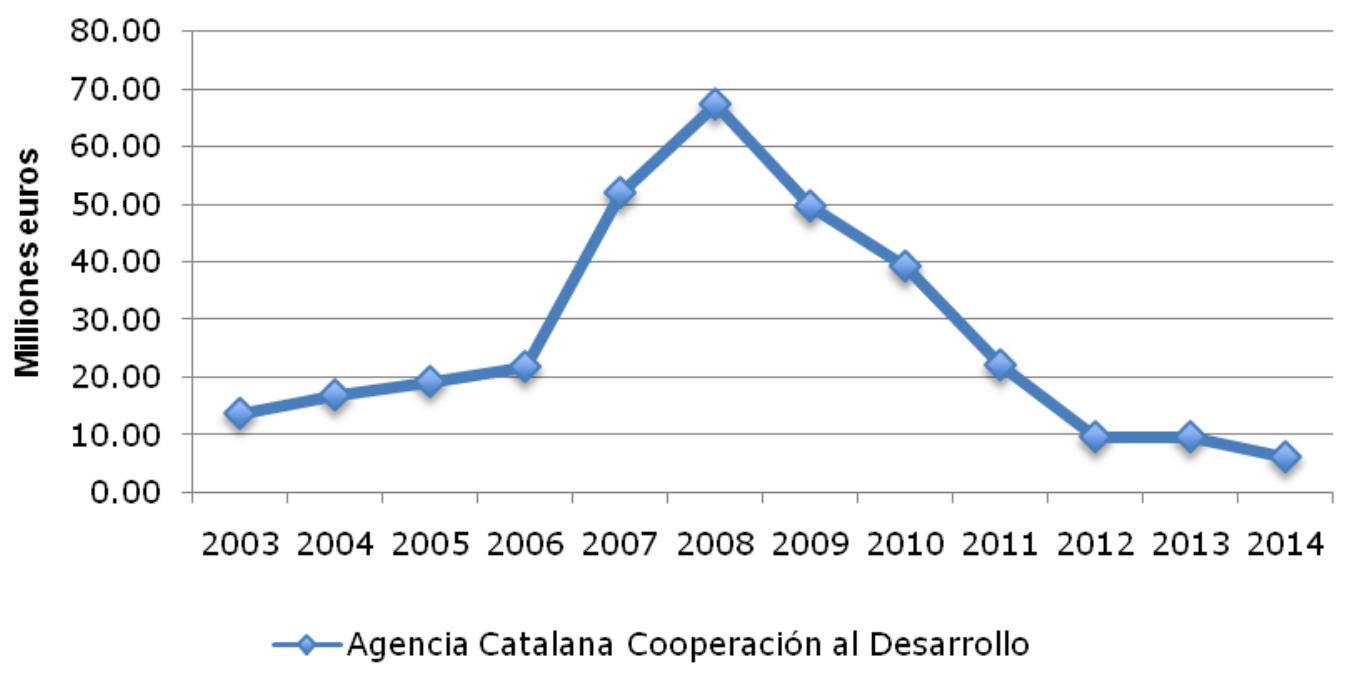

Gráfico 1: Reducción presupuestaria de la partida de cooperación al desarrollo. Elaboración propia.

Fuente: pla director 2003-2006; pla director 2007-2010; Llei 6/2011, del 27 de juliol; Llei 1/2012, del 22 de febrer; Llei 1/2014, del 27 de gener.

En otro orden de hechos, entre 2012 y junio de 2014 no se abrió ninguna convocatoria de subvenciones ${ }^{8}$ y la Generalitat, en junio de 2014, aún tenía deudas con las ONG de las resoluciones aprobadas en 2010. A la disminución de ingresos presupuestarios, los impagos y la falta de subvenciones de los últimos tres años se le atribuye un cambio de discurso de la política de cooperación catalana (Badia et al. 2013). La Federación Catalana de ONG por la Paz, los Derechos Humanos y el Desarrollo valora que estos cambios afectan a la identidad de la cooperación y apunta a una transformación hacia una "cooperación empresarial"9.

\section{Metodología}

Para la selección de la ONG donde realizar el estudio de caso se tuvo en cuenta la variable financiamiento. En primer lugar, analicé las resoluciones de las

8 A finales de junio de 2014 la ACCD publicó una convocatoria de subvenciones para proyectos de educación para el desarrollo.

${ }^{9}$ Entrevista 1: 24/02/2014, Barcelona. 


\section{perifèria}

Número 20 (1), junio 2015

http://revistes.uab.cat/periferia

subvenciones aprobadas en la convocatoria de programas de 2010 y proyectos $2011^{10}$, y observé que el importe total de los proyectos y programas previstos para hacer en Guatemala era el más elevado. En segundo lugar, seleccioné a la ONG que tenía subvenciones aprobadas por la ACCD para programas 2010 y proyectos 2011. La ONG resultante fue Alternativa. Intercanvi amb els Pobles Indígenes.

Los métodos que se han usado para realizar la investigación han sido la recogida y el análisis de datos cuantitativos y cualitativos. Referente a los datos cuantitativos, se han recopilado y analizado fuentes documentales de la ACCD, la Generalitat de Catalunya y de la ONG Alternativa. Relativo a los datos cualitativos se han realizado un total de diez entrevistas semi-estructuradas a tres grupos diferenciados: en Barcelona a tres miembros de la Federació Catalana d'ONG per la Pau, els Drets Humans i el Desenvolupament (FCONG) ${ }^{11}$, a los tres técnicos de AlterNativa, y a cuatro profesionales de COINDI en Guatemala. De forma complementaria se ha llevado a cabo observación participante durante el trabajo de campo en la sede de AlterNativa en Barcelona, los meses de marzo y abril de 2012 y en la sede de COINDI en Sololá (Guatemala) el mes de mayo de 2014. También se ha realizado observación no participante en los seis talleres que COINDI ha impartido en las comunidades donde he participado como observadora. El motivo de la elección de esta última técnica es el desconocimiento de las lenguas mayas -cachiquel y quiché- que hablan las beneficiarias de los proyectos y los profesionales.

\section{El caso de AlterNativa. Intercanvi amb els Pobles Indígenes}

El objetivo de AlterNativa es la promoción y difusión de propuestas sociales, económicas y ambientales alternativas a los modelos hegemónicos y homogeneizadores de desarrollo. Por este motivo la entidad apoya los procesos de

\footnotetext{
10 Ver el apartado "La cooperación al desarrollo en Cataluña".

${ }^{11}$ Aclarar que aunque la FCONG no forma parte de la unidad de observación, se entrevistó a tres de sus miembros por el papel que tiene ésta como representante de las ONG catalanas. En junio de 2014 cambió de nombre y pasó a llamarse Lafede.cat-Organitzacions per a la Justícia Global.
} 


\section{perifèria}

Número 20 (1), junio 2015

http://revistes.uab.cat/periferia

desarrollo de los pueblos indígenas que contemplan la diversidad cultural, la justicia social y la sostenibilidad ambiental ${ }^{12}$.

Desde el año 2007 el equipo de trabajo de AlterNativa ha estado formado por tres técnicos a jornada completa (aunque en algún período hubo un cuarto técnico). Cada uno de estos profesionales es responsable de un área determinada: Proyectos América del Sur, Educación para el desarrollo y Proyectos América Central. Uno de ellos es el coordinador, el otro el secretario de la junta directiva y el tercero, responsable de comunicación. Sin embargo, los tres están de acuerdo en que todos hacen un poco de todo, desde tareas de gestión a actividades en las que participan todos juntos, como la organización de la Muestra de Cine Indígena.

AlterNativa también cuenta con el apoyo y la colaboración de personal voluntario y alumnos en prácticas de la carrera de Antropología Social y Cultural de la Universidad de Barcelona y de la Universidad Autónoma de Barcelona.

La entidad tiene dos líneas de trabajo. La primera, la cooperación con los pueblos indígenas, que apoya el reconocimiento y ejercicio efectivo de los derechos individuales y colectivos y potencia sus propios modelos de autodesarrollo. Y la segunda, el intercambio cultural a través de la investigación, promoción y difusión de alternativas sociales surgidas de las experiencias de trabajo con los pueblos indígenas y sus organizaciones. Combinar cooperación e investigación, sobre todo en el ámbito de la antropología social, la distingue de otras entidades dedicadas a la cooperación.

Para dar apoyo a organizaciones indígenas, AlterNativa, a lo largo de su historia, ha implementado más de 65 proyectos de cooperación al desarrollo en Guatemala, Nicaragua, Brasil, Perú y Ecuador y de educación para el desarrollo en el Estado español y en América Latina. Sin embargo, por motivos de insuficiente conocimiento de la zona, de relaciones con las contrapartes basadas exclusivamente en la financiación y no en el intercambio, de falta de liderazgo de

12 AlterNativa. Intercanvi amb els Pobles Indígenes, ed. (s.d.). Memòria 1986-2006. 20 anys treballant per un món més just i divers. 


\section{perifèria}

Número 20 (1), junio 2015

http://revistes.uab.cat/periferia

las contrapartes en las comunidades o de excesiva dependencia de la cooperación internacional, desde el año 2004 trabaja exclusivamente en el Estado español, en Guatemala y en Perú. Complementariamente a los proyectos, AlterNativa participa en acciones de denuncia y de incidencia.

La sede social de AlterNativa está ubicada en la ciudad de Barcelona. Desde el mes de junio de 2014 AlterNativa comparte oficina con otras ONG (Entrepobles, Brigades de Pau Internacional y el Institut de Drets Humans de Catalunya).

\section{Efectos de la reducción del financiamiento de la política de cooperación catalana en la ONG AlterNativa}

La disminución del presupuesto público de la Generalitat de Cataluña destinado a la política de cooperación al desarrollo ha afectado a las ONG catalanas. Según la FCONG, la reducción económica ha provocado la desaparición de entidades, la reducción de personal que ha sido sustituido por personal voluntario, la aplicación de expedientes de regulación de empleo, tener que compartir locales con otras ONG y la necesidad de captar socios y buscar nuevas fuentes de financiación, sobre todo con la mirada puesta en la Unión Europea.

En el caso de AlterNativa, como explicaré a continuación, la disminución de financiación ha afectado a nivel económico, a la ejecución de los proyectos, a la situación contractual del personal, a la infraestructura y a la dinámica interna del equipo de trabajo.

En primer lugar, la disminución del presupuesto público de la Generalitat de Cataluña ha afectado a la estabilidad económica de AlterNativa. Entre 2003 y 2009 el presupuesto de la entidad fue in crescendo, siendo el 2009 el año con el presupuesto más elevado. A partir del año 2010, en correlación a la reducción de financiación de la Generalitat, el presupuesto empezó a disminuir. Este año se redujo un 23,99\% respecto al anterior ejercicio, en 2011 un 7,47\% más que en 


\section{perifèria}

Número 20 (1), junio 2015

http://revistes.uab.cat/periferia

2010, en 2012 un 23,31\% respecto al año anterior y en 2013 un 42,09\% respecto $2012^{13}$.

La principal fuente de financiación de la entidad han sido las administraciones públicas, como la Agencia Catalana de Cooperación al Desarrollo (ACCD), la Agencia Española de Cooperación Internacional al Desarrollo (AECID) y Ayuntamientos (Barcelona y Cerdanyola, por ejemplo). En el pasado también recibieron financiación del Col•legi d'Advocats o de la Fundación "la Caixa", entre otros.

Desde la creación de la ACCD hasta 2011, la Generalitat fue el principal financiador de AlterNativa, muy por encima de otras instituciones públicas y privadas. Esta constante se rompe con la política de "recortes" decretada por el gobierno catalán.

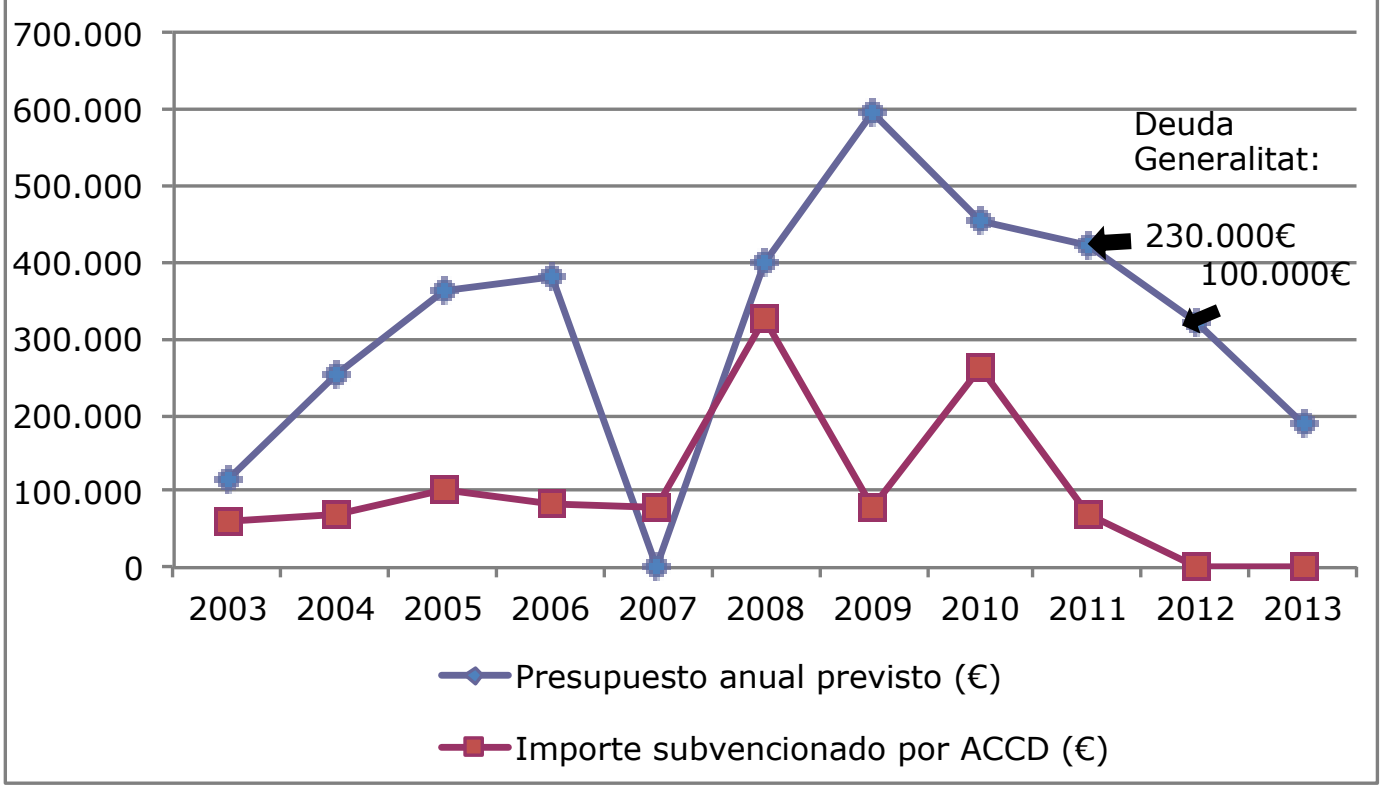

Gráfico 2: Evolución presupuestaria e importes recibidos de subvenciones públicas de la ACCD

* Elaboración propia a partir de datos facilitados por la entidad.

2007: Datos no disponibles.

13 El período analizado va desde el 2003, año de creación de la ACCD, hasta 2013, último año de los datos facilitados por la entidad. 


\section{perifèria}

Número 20 (1), junio 2015

http://revistes.uab.cat/periferia

La principal consecuencia de la reducción de financiación de la Generalitat en cooperación tuvo sus peores efectos en los impagos de los importes concedidos a las entidades. En el año 2011 la ACCD publicó la convocatoria y aprobó subvenciones para proyectos y programas con la regularidad usual. Ese mismo año asumió la dirección de la Agencia Carles Llorens, quien muy pronto, alegando dificultades de la tesorería de la Generalitat, anunció la suspensión de los pagos de subvenciones aprobadas en 2010 y 2011. Debido a este motivo, la Generalitat incurrió en una deuda con AlterNativa de $230.000 €$ por las transferencias correspondientes al año 2011 y $100.000 €$ en 2012.

A partir de este hecho surgieron los problemas financieros de la entidad. Al no recibir los pagos de la Generalitat se empezaron a cubrir los gastos con el saldo disponible: "los años 2011, 2012 fueron un debacle, y en 2013 ya no teníamos fondos" (Ramón ${ }^{14}$ ). Esto obligó a AlterNativa a tomar medidas en términos de contratación, revisar partidas y reducir gastos para el funcionamiento de la entidad. La deuda de la Generalitat, en junio de 2014, aún no había sido liquidada.

Por otra parte y de acuerdo con lo mencionado previamente, los impagos anunciados por la Generalitat en 2011 tuvieron repercusiones directas en el funcionamiento y la estabilidad de la entidad y en la ejecución de proyectos ${ }^{15}$. Entre 2003 y 2011 recibieron financiación de la Agencia Catalana un total de 15 proyectos o programas de AlterNativa, de los cuales resultaron afectados por los impagos un programa en Perú, uno en Barcelona y un proyecto en Guatemala ${ }^{16}$.

\footnotetext{
14 Entrevista 5: 29/04/2014, Barcelona.

15 Ver epígrafe: Relación entre AlterNativa y Cooperación Indígena para el Desarrollo.

16 IDEM
} 


\section{perifèria}

Número 20 (1), junio 2015

http://revistes.uab.cat/periferia

"Mejora del control sostenible de los recursos naturales y la protección del territorio ancestral del pueblo Quechua de la cuenca del río Pastaza" (Perú)

\begin{tabular}{|c|c|c|c|}
\hline Contraparte & \multicolumn{3}{|c|}{ Federación Indígena Quechua del Pastaza (FEDIQUEP) } \\
\hline Duración del programa & \multicolumn{3}{|l|}{3 años } \\
\hline Importe total & \multicolumn{3}{|l|}{$240.000 €$} \\
\hline Importe anual previsto & $80.000 €$ & $80.000 €$ & $80.000 €$ \\
\hline Fecha prevista pago & 2010 & 2011 & 2012 \\
\hline Fecha real pago & 2010 & 2013 & $\begin{array}{l}\text { Pendiente } \\
\text { Abril } 2014\end{array}$ \\
\hline
\end{tabular}

Tabla 1: Presentación programa "Mejora del control sostenible de los recursos naturales y la protección del territorio ancestral del pueblo Quechua de la cuenca del río Pastaza" (Perú).

* Elaboración propia.

Ante la situación producida por los impagos, AlterNativa decidió informar a la contraparte, la cual siguió con la ejecución del proyecto sin contar con el apoyo económico de AlterNativa (esta no disponía de fondos suficientes para asumir el coste del proyecto y no quería pedir créditos bancarios porque podían poner a la entidad en situación de deuda). Los impagos supusieron una pérdida de confianza de la contraparte hacia AlterNativa. Al recibir la financiación, AlterNativa readaptó el proyecto a la situación de la entidad de Perú. 


\section{perifèria}

Número 20 (1), junio 2015

http://revistes.uab.cat/periferia

\begin{tabular}{|l|l|}
\hline $\begin{array}{l}\text { "Consolidación del Movimiento Regional de mujeres mayas de Sololá para la } \\
\text { promoción de la incidencia social y política de la mujer indígena" (Guatemala) }\end{array}$ \\
\hline Contraparte: & Cooperación Indígena Para el Desarrollo Integral (COINDI) \\
\hline Duración del programa & 1 año \\
\hline Importe total & $70.000 €$ \\
\hline Importe anual previsto & $70.000 €$ \\
\hline Fecha prevista pago & $\mathbf{2 0 1 1}$ \\
\hline Fecha real pago & $\mathbf{2 0 1 3}$ \\
\hline
\end{tabular}

Tabla 2: Presentación proyecto "Consolidación del Movimiento Regional de mujeres mayas de Sololá para la promoción de la incidencia social y política de la mujer indígena" (Guatemala).

Elaboración propia.

Debido a los impagos, AlterNativa decidió no iniciar este proyecto en los plazos establecidos porque no disponía de suficientes fondos propios y no quería pedir créditos bancarios. El proyecto se inició cuando la Generalitat dio la financiación dos años más tarde. Esto afectó a los plazos previstos de ejecución del proyecto pero no a la relación de la entidad con la contraparte ${ }^{17}$.

17 IDEM 


\section{perifèria}

Número 20 (1), junio 2015

http://revistes.uab.cat/periferia

\begin{tabular}{|l|l|l|l|}
$\begin{array}{l}\text { "Sensibilización, formación y promoción del derecho al territorio, el derecho a la } \\
\text { diversidad cultural y el derecho a la consulta de los pueblos indígenas a través del } \\
\text { (Mudiovisual" } \\
\text { auntra Cinema Indígena, Barcelona) }\end{array}$ \\
\hline Duración del programa & 3 años & $20.000 €$ & $20.000 €$ \\
\hline Importe total & $60.000 €$ & $\mathbf{2 0 1 1}$ & $\mathbf{2 0 1 2}$ \\
\hline Importe anual previsto & $20.000 €$ & $\mathbf{2 0 1 3}$ & Pendiente \\
\hline Fecha prevista pago & 2010 & Abril 2014 \\
\hline Fecha real pago & 2010 & &
\end{tabular}

Tabla 3: Presentación programa "Sensibilización, formación y promoción del derecho al territorio, el derecho a la diversidad cultural y el derecho a la consulta de los pueblos indígenas a través del audiovisual".

* Elaboración propia.

En este caso, AlterNativa decidió continuar con el proyecto sin contar con los fondos de la ACCD. Las dos últimas ediciones se realizaron gracias a la cofinanciación del Ayuntamiento de Barcelona y al hecho de formar parte de la Coordinación por los Derechos de los Pueblos Indígenas, ya que a través de esta, se facilitó el viaje de los líderes indígenas que participaron en las dos últimas ediciones de la Muestra.

En tercer lugar, además de las consecuencias económicas y las consecuencias en los proyectos y programas, el efecto de los recortes también ha repercutido en la dinámica interna del equipo técnico de AlterNativa, ya que ha tenido que ir adaptando la gestión y ajustando la ejecución de los proyectos en función de los imprevistos. Para una de las integrantes del equipo, fue a raíz de estas circunstancias que comenzaron los "bailes de incertidumbre", y esto provocó una especie de agotamiento: "hoy hacemos unos planes, mañana los cambiamos y 


\section{perifèria}

Número 20 (1), junio 2015

http://revistes.uab.cat/periferia

los volvemos a cambiar día a día. [...] se ha gastado mucha energía en gestionar esto" (Telma $\left.{ }^{18}\right)$.

En las entrevistas se constata la aparición de la inseguridad como un nuevo elemento del funcionamiento del equipo humano. Hasta hace poco la entidad trabajaba a un año vista, es decir, cada año se presentaban proyectos o programas a convocatorias, con la certeza de que serían aprobados y obtendrían la financiación necesaria para su continuidad profesional. El panorama cambia debido a factores como la suspensión de convocatorias, el aumento de competitividad entre las ONG para conseguir financiación y la reducción de líneas prioritarias de algunos financiadores.

La incertidumbre también se traduce en la estabilidad contractual de los trabajadores. En 2013 como consecuencia de la falta de financiación de la ACCD, la disponibilidad de fondos de la entidad sólo llegaba para pagar el sueldo de los trabajadores durante cinco meses.

Como salida a esta situación, se decidió aplicar un expediente de regulación de empleo (ERE) a dos técnicos durante un año con una reducción de su jornada laboral ${ }^{19}$. A pesar del ERE ambos profesionales continuaron haciendo tareas extras, entre ellas participar en las redes y buscar financiación para asegurar la continuidad de la entidad. Como bien explica Ramón, se trataba de una sobre dedicación laboral:

\footnotetext{
"Tener menos proyectos a veces no significa tener menos trabajo, hay toda una parte que no es remunerada: buscar convocatorias, participar en redes. [...] El comentario sobre los recortes podría ser: menos sueldo, pero misma dedicación." (Ramón ${ }^{20}$ )
}

\footnotetext{
18 Entrevista 3: 14/04/2014, Barcelona.

19 Durante la realización de la investigación estos dos trabajadores volvían a estar contratados a jornada completa.

20 Entrevista 5: 29/04/2014, Barcelona.
} 


\section{perifèria}

Número 20 (1), junio 2015

http://revistes.uab.cat/periferia

Actualmente, tanto la incertidumbre laboral como la inestabilidad de la entidad siguen condicionando el funcionamiento del equipo humano de AlterNativa. Dos de los tres técnicos consideran mínimas las opciones de conseguir financiación para cubrir los gastos de personal en un futuro inmediato. Vinculado a esto, a mediados de junio de 2014, la sede social de AlterNativa se trasladó a un espacio de coworking. Una de las razones para dejar el piso donde estaba ubicada la antigua sede y decidir trasladarse a una oficina compartida es que la nueva sede permite la adaptación a la situación del equipo técnico.

El escenario resultante de las consecuencias descritas plantea algunos interrogantes sobre el futuro de la entidad y la obliga a buscar nuevas vías de financiación para poder garantizar su continuidad. Hasta el momento, la única estrategia que se ha llevado a cabo es presentar proyectos a la Unión Europea, si bien todavía no ha recibido ninguna subvención.

Ante la necesidad emergente de conseguir financiación, se plantean dos limitaciones que condicionan el éxito de la captación de fondos. En primer lugar, la dedicación casi exclusiva del equipo técnico se corresponde con el "proyectorado" (Badia et al. 2013). Los técnicos centran su trabajo en la búsqueda de financiación, la gestión, el seguimiento y la justificación de proyectos. Este hecho provoca que no dispongan de tiempo para buscar nuevas fuentes de financiación y para otras tareas necesarias para la entidad. $Y$ en segundo lugar, los criterios ideológicos que excluyen ciertas fuentes de financiación que justamente ahora son las más accesibles. Se descarta obtener recursos económicos de entidades bancarias aunque en algún momento de su historia no fuera así-, de empresas privadas y de campañas sensacionalistas. Solicitar financiamiento a entidades bancarias o empresas privadas supondría entrar en colisión con el ideal de la entidad, obligaría a AlterNativa a cambiar el discurso y sería contradictorio con algunas de las acciones que realiza.

Y para finalizar, en relación con a la perspectiva de futuro de la entidad, se puede dar el caso de que su dinámica se transforme y pase de ser una entidad regida por la lógica del proyecto y con una relación burocratizada con la administración, a una entidad con un perfil de voluntariado que no depende de financiadores públicos 


\section{perifèria}

Número 20 (1), junio 2015

http://revistes.uab.cat/periferia

(Badia et al. 2013). Como comenta Trini: "Los recortes han hecho que nuestra perspectiva de futuro sea bastante magra y que casi tengamos un deadline" $\left(\right.$ Trini $\left.^{21}\right)$. En caso de que los contratos lleguen a su fin, dos miembros del equipo técnico tienen claro que seguirán colaborando con la entidad. Tal vez no realizarán proyectos de cooperación pero seguirán vinculados a acciones de incidencia y de difusión, por ejemplo a través la realización de la Muestra de Cine Indígena. Este vínculo se mantendrá porque para todos ellos formar parte de AlterNativa, como trabajadores o voluntarios, es un posicionamiento político frente a las estructuras sociales y el "orden mundial".

\section{Contraparte de AlterNativa: Cooperación Indígena para el Desarrollo Integral}

La asociación Cooperación Indígena para el Desarrollo Integral (COINDI) se creó en 1986, durante el conflicto armado interno en Guatemala, con el fin de luchar contra la situación de discriminación, desigualdad social y la desarticulación organizativa de los pueblos indígenas.

COINDI tiene la sede en la ciudad de Sololá y trabaja en las comunidades de los municipios de Sololá, Nahualá y Santa Catarina de Ixtahuacán.

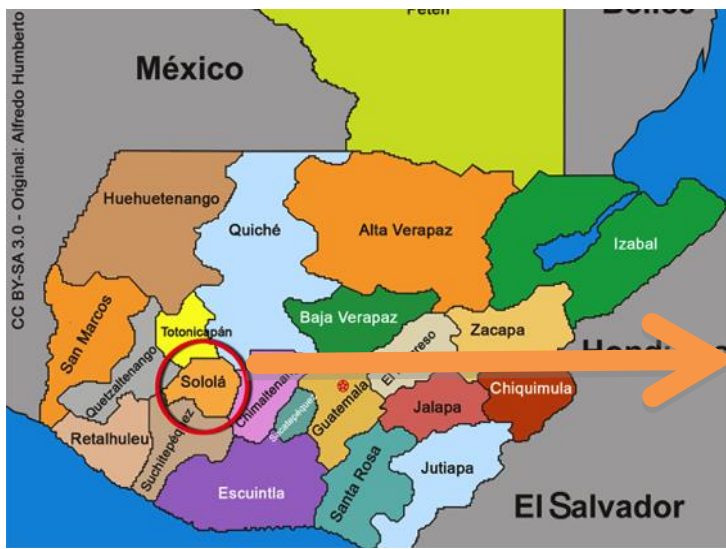

Fuente: http://www.pazenguatemala.org/dondeestamos

21 Entrevista 4: 15/04/2014, Barcelona.

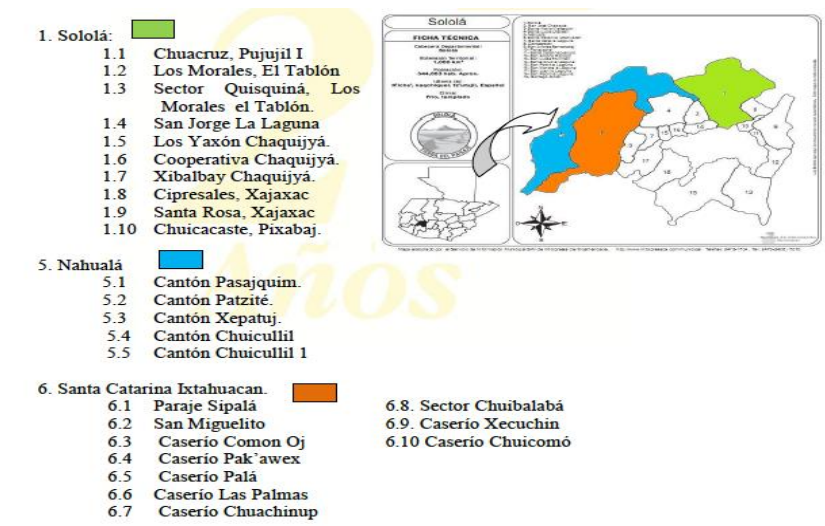

Fuente: Cooperación Indígena para el Desarrollo Integral, ed. (s.d). Memoria labores del 2011 


\section{perifèria}

Número 20 (1), junio 2015

http://revistes.uab.cat/periferia

El objetivo de COINDI es fomentar el desarrollo integral de las comunidades de Sololá a través de proyectos que impulsen la igualdad entre la ciudadanía, con especial énfasis en las mujeres y los jóvenes. Según una de las directoras, COINDI se diferencia de otras organizaciones porque trabaja con una perspectiva de pertenencia cultural y de rescate de la identidad maya, a través del uso de las lenguas mayas ${ }^{22}$-principalmente del cachiquel-, de la celebración de días de la espiritualidad maya y de la incorporación de aspectos de la cultura maya en todas sus actividades.

En relación con el equipo humano, la media anual de trabajadores de la entidad es de 20 , ya que el número de profesionales varía a lo largo del año en función de los requerimientos de los proyectos que se estén ejecutando.

COINDI tiene tres líneas de trabajo ${ }^{23}$ :

- Fortalecimiento del tejido organizativo a nivel comunitario.

- Organización y formación política de mujeres y jóvenes.

- Seguridad alimentaria y economía familiar.

Paralelamente, COINDI tiene el objetivo de establecer alianzas con organizaciones afines para hacer incidencia política a nivel local, municipal, departamental y nacional y elaborar propuestas políticas a favor de los pueblos indígenas ${ }^{24}$.

Destacar que todos los entrevistados convienen en que la formación política es el rasgo diferencial de las acciones de COINDI y que esto los distingue de las intervenciones asistencialistas que realizan otras entidades o el propio gobierno. Por otra parte, según comentan, un buen número de personas que han pasado por la entidad, ya sea como socios, trabajadores o beneficiarios de los proyectos, después han ocupado cargos políticos en las alcaldías municipales, las alcaldías

\footnotetext{
22 En Guatemala se hablan 22 lenguas mayas, además del español y el garífuna. Las principales son quiché' (hablado por 2.330.000 personas), q'eqchi (800.000) y mam (530.000). (Ethnologue. Languages of the World).

23 Entrevista 8: 13/05/2014, Sololá.

24 Cooperación Indígena para el Desarrollo Integral, ed. (s.d). Memoria de labores 2011.
} 


\section{perifèria}

Número 20 (1), junio 2015

http://revistes.uab.cat/periferia

indígenas o han participado en otros estamentos gubernamentales, como los COCODE o los COMUDE25.

Por otra parte, según el contable ${ }^{26}$, desde el año 2003 la entidad ha contado con un presupuesto medio anual de 3.000.000 quetzales $(282.694,89 €)$. Los ingresos de la entidad provienen de fondos propios y de la cooperación internacional.

Los fondos de la cooperación internacional provienen de Bélgica, Canadá, España, Noruega y Suecia. El 95\% de los ingresos del presupuesto del año 2013 provenían de estos fondos.

Para todos los miembros de COINDI, las dotaciones económicas de la cooperación internacional son imprescindibles para poder continuar con el trabajo de la entidad, ya que el gobierno desacredita y no apoya a organizaciones como COINDI (que son vistas como subversivas).

Por otro lado, sobre la relación entre AlterNativa y Cooperación Indígena para el Desarrollo Integral, todos los proyectos que se han realizado entre ambas entidades entre el año 2007 al 2013 (exceptuando el 2012), han sido subvencionados por la Agencia Catalana de Cooperación al Desarrollo. La mayoría de los técnicos de COINDI afirman que coincidiendo con la implementación del programa "Promoción de la capacidad de incidencia social y política de la mujer indígena para el ejercicio efectivo de sus derechos individuales y colectivos" de 2008 a 2011, AlterNativa fue el principal financiador de la entidad. Este programa contemplaba un gran abanico de actividades dirigidas a más de 24 grupos de mujeres de las comunidades de los municipios de Sololá, Nahualá y Santa Catarina Ixtahuacán ${ }^{27}$.

25 Los COCODE son la estructura comunitaria para fomentar la participación de la ciudadanía en la gestión pública de las comunidades y los COMUDE son la estructura comunitaria para fomentar la participación de la ciudadanía en la gestión pública del municipio (un municipio representa una agrupación de varias comunidades).

26 Los datos disponibles provienen de las entrevistas. Solicité a COINDI documentación sobre los presupuestos anuales pero no se me facilitó.

27 AlterNativa. Intercanvi amb els Pobles Indígenes, ed. (s.d.). Informe final per a programes de cooperació al desenvolupament i solidaritat internacional (codi convocatòria PR2008). 


\section{perifèria}

Número 20 (1), junio 2015

http://revistes.uab.cat/periferia

Si bien hasta 2011 había existido una relación sin ningún obstáculo económico entre AlterNativa y COINDI, ese mismo año se formuló el proyecto "Consolidación del Movimiento Regional de Mujeres Mayas de Sololá" para consolidar parte de los resultados del programa mencionado. La ACCD lo aprobó con una subvención de $70.000 €$, pero a raíz de los impagos del gobierno catalán el proyecto se tuvo que postergar casi dos años a la espera de que se hiciera efectiva la dotación económica. Este proyecto tenía la finalidad de consolidar y promover el "Movimiento Regional de Mujeres Mayas de Sololá", principalmente a través de reuniones y asambleas de organizaciones de mujeres y de cursos de formación política y liderazgo 28 . La situación resultante de los impagos a las ONG obligó a COINDI a reunirse con sus socios para decidir si podían poner en marcha el proyecto sin contar con la financiación de la ACCD. Se vio que no era posible asumir los costes que éste comportaba y se decidió posponerlo. A pesar de esta decisión formal, según las profesionales que trabajaron en el proyecto, las mujeres que ya formaban parte del movimiento resolvieron continuar con las reuniones y solicitar apoyo a COINDI. Sin la financiación de la Agencia Catalana, COINDI no podía asumir el $100 \%$ del coste de estas reuniones ${ }^{29}$, pero decidió apoyarlas de una forma menos regular de la que estaba prevista y cubrir algunos de los gastos con fondos propios de la entidad y con recursos de PROSOL (ONG de Canadá). En 2013, el proyecto se ejecutó tal como estaba planificado originalmente en 2011.

Los efectos de los impagos se notaron también en COINDI, obligando a la entidad a hacer reducción de los gastos ordinarios, ya que parte de estos se cubren con fondos de la cooperación internacional.

En 2012, AlterNativa presentó un proyecto de COINDI a la ACCD, pero no se llevó a cabo porque fue la convocatoria que el gobierno catalán canceló. El año 2013, la ACCD no abrió la convocatoria y AlterNativa no presentó ningún proyecto con COINDI a ninguna otra financiadora.

\footnotetext{
28 AlterNativa. Intercanvi amb els Pobles Indígenes, ed. (s.d.). Informe final de la convocatòria de subvencions destinades a donar suport a projectes en l'àmbit de cooperació al desenvolupament (codi de la convocatòria CD2011).

29 COINDI cubre el coste del transporte y de la alimentación de las mujeres que participan en las asambleas, las capacitaciones, los talleres, etc.
} 


\section{perifèria}

Número 20 (1), junio 2015

http://revistes.uab.cat/periferia

Trascendiendo estas cuestiones, los cambios en la política catalana de la cooperación de la Generalitat y consecuentemente la disminución de financiación, no han afectado la relación entre COINDI y AlterNativa. La comunicación entre ellas sigue vigente y además, en junio de 2014 ambas participaban, junto con otras entidades del Estado español, Colombia, Ecuador, Guatemala y Bolivia en el proyecto "Escuelas Indígenas de Formación Política", proyecto liderado por la Coordinación por los Derechos de los Pueblos Indígenas (CODPI).

Para los miembros entrevistados de AlterNativa y COINDI, los elementos imprescindibles y claves de la relación son:

- Confianza: se reconoce como el elemento fundamental de la relación entre las dos entidades y la definen en términos de amistad.

- Transparencia: aspecto esencial que debe darse en un relación de confianza y que se determina a partir de la veracidad y calidad de la información compartida ya sea de los proyectos, de la situación de cada entidad, de la situación del país, etc.

- Intercambio: elemento clave en la relación mediante la transferencia de conocimientos, como por ejemplo, formas de vivir alternativas al modelo occidental, como podría ser "el buen vivir" 30.

En el caso de AlterNativa el intercambio es fundamental para construir y consolidar la relación, ya que huyen del rol de ONG "financiadora", tal y como expone Ramón: "[COINDI] es una contraparte con la que tenemos un feedback muy bueno. Han entendido nuestro planteamiento de intercambio, que a veces cuesta romperlo con las contrapartes que [...] te ven como 'el financiador'." (Ramón ${ }^{31}$ ).

Por otra parte, para ambas entidades la relación va más allá de la transferencia de recursos económicos, se concibe como un apoyo político. AlterNativa asegura que tiene mucho cuidado en la elección de las contrapartes, tal y como expone Telma:

30 Filosofía surgida en la región andina durante la última década. El concepto hace referencia a las categorías de suma qamaña (aimara) y allin kawsay o sumak kawsay (quechua). Significa una vida digna y concibe el bienestar de una forma holística, en harmonía con la comunidad, la naturaleza y el entorno sobrenatural (Viola 2014).

31 Entrevista 5: 29/04/2014, Barcelona. 


\section{perifèria}

Número 20 (1), junio 2015

http://revistes.uab.cat/periferia

"la contraparte que tú elijas es la idea política que apoyas" 32 y trabajar con una determinada contraparte es como "casarse"33. Por su parte, las directoras de COINDI, también atribuyen a las ONG y a las agencias de cooperación internacional el rol de aliados políticos. Para estas profesionales es importante que el agente de cooperación internacional no imponga el trabajo, sino que respete la autonomía de la organización y de las comunidades.

En cuanto a la relación económica entre las ONG a la hora de presentarse a convocatorias públicas de subvenciones, AlterNativa actúa como una ONG mediadora34 (Martínez 2010) entre la contraparte y la institución financiadora. AlterNativa informa a la contraparte de las convocatorias a las que se puede acoger, esta envía una primera formulación del proyecto y AlterNativa la reformula según los códigos, las categorías y los parámetros del financiador. Así pues, AlterNativa dispone de los conocimientos necesarios que la sitúan en una posición de mediadora.

\section{La cooperación internacional y el rol político vs el rol económico}

Los entrevistados de la FCONG y AlterNativa justifican la cooperación internacional en referencia a la lucha y a la transformación de las estructuras políticas y económicas. Este es el significado que atribuyen a cooperación y que, al mismo tiempo, determina sus principios ideológicos. Para los entrevistados se parte de una visión global que vincula la responsabilidad que tienen los países del Norte frente a la vulneración de derechos en los países del Sur, producida por las relaciones de poder.

La transformación de las estructuras sociales y políticas, a ojos de AlterNativa, se realiza a través de procesos de incidencia política, de denuncia de vulneración de derechos de los pueblos indígenas por parte de las empresas transnacionales, y de

\footnotetext{
32 Diario de campo: 27.

33 Diario de campo: 26.

34 Para Martínez (2010) las ONG mediadoras son las que favorecen la transferencia de recursos a nivel local. Aunque AlterNativa no media para conseguir recursos directamente para el ámbito local, asume un rol de mediadora entre las instituciones financiadoras y las contrapartes.
} 


\section{perifèria}

Número 20 (1), junio 2015

http://revistes.uab.cat/periferia

dar apoyo político a organizaciones indígenas. Vinculado con esta lucha, tanto la FCONG como AlterNativa, hablan de cooperación transformadora y no de cooperación al desarrollo.

Por otra parte, el significado que los entrevistados de Guatemala atribuyen a cooperación hace referencia a los agentes de cooperación internacional. Para las directoras de COINDI, cooperación son las ONG y las agencias internacionales que financian, dan apoyo técnico y político a las acciones que realiza la entidad. Para el resto de miembros de COINDI, cooperación alude a la transferencia de recursos económicos y hablan de "cooperación internacional financiera" ${ }^{35}$ y "de fondos de la cooperación"36. Ninguno de ellos lo atribuye a las circunstancias generadas de las relaciones de poder entre países del Norte y del Sur. Consideran que los objetivos que se plantean en los proyectos financiados por las agencias y las ONG internacionales deberían ser una responsabilidad asumida por el gobierno guatemalteco.

Por otra parte, dada la relación que mantienen COINDI y AlterNativa, una de las directoras de COINDI conoce la situación de los recortes de la Generalitat en el sector de la cooperación. Tanto para ella como para los entrevistados de la FCONG y de AlterNativa, la disminución de financiación ha respondido a una decisión política $^{37}$ y según la FCONG y AlterNativa, el gobierno no se ha responsabilizado de su rol como representante de la sociedad civil que reclama -de acuerdo con las entidades entrevistadas- la transformación de las estructuras políticas y económicas entre países del Norte y del Sur. Según un miembro de la FCONG:

"Como sociedad tenemos parte de responsabilidad de lo que ocurre en los países del Sur y de lo que ha pasado históricamente. Es responsabilidad de los

\footnotetext{
35 Comunicación personal: Conversación 14/05/2014, Sololá (Diario de campo: 128).

36 Entrevista 10: 22/05/2014, Sololá.

37 La reducción de partidas presupuestarias se realizó cuando el sr. Carles Llorens dirigía la ACCD. Llorens dimitió el día 11 de febrero de 2014. El 18 de febrero de 2014 se nombró a Marta Macías como la directora. Bajo su dirección se han producido cambios en la dinámica de la ACCD. Habrá que ver los acontecimientos que vayan sucediendo con la nueva directora y observar como el sector se va reestructurando.
} 


\section{perifèria}

Número 20 (1), junio 2015

http://revistes.uab.cat/periferia

gobiernos de los países del Norte trabajar para que en los países del Sur la gente pueda tener acceso al unos derechos básicos. Por lo tanto, por eso entiendo que es una responsabilidad política." ( $\left.\mathrm{Pau}^{38}\right)$.

En relación con esta responsabilidad, tanto para la FCONG como para AlterNativa, a nivel político se ha utilizado la crisis económica para desmantelar el sector de la cooperación al desarrollo. Así, la crisis ha sido: "la excusa perfecta para eliminar todo este aspecto de la incidencia política y de gente que molesta" (Trini ${ }^{39}$ ). También, algunos de los entrevistados consideran que la reducción de la financiación pública y la introducción de la empresa privada como agente de la cooperación, se corresponde con un cambio de orientación de la política pública de la Agencia Catalana de Cooperación al Desarrollo.

\section{Conclusiones}

En primer lugar, en relación con el contexto catalán, la menor significación de la Ayuda Oficial al Desarrollo por parte de la Generalitat se corresponde con uno de los elementos que se atribuyen a la crisis de la cooperación internacional (Unceta 2013). Asimismo, la disminución de la financiación y la introducción de la empresa privada como agente de la cooperación son hechos que apuntan a una transformación de la política pública de la cooperación al desarrollo.

Por otra parte, una de las características que cabe destacar del caso estudiado es que la ONG AlterNativa. Intercanvi amb els Pobles Indígenes, como muchas otras ONG, es una entidad profesionalizada que depende de financiación pública. De acuerdo con algunos de los determinantes que señalan Badia et al. (2013) la dependencia económica de AlterNativa a las subvenciones ha tenido dos consecuencias. En primer lugar, los requisitos que exige presentarse a las convocatorias de subvenciones públicas, ha provocado un exceso de tecnificación de la entidad. $Y$ en segundo lugar, hasta ahora la entidad se ha regido por la lógica del proyecto, siendo este su elemento central y su unidad de financiación. Esto ha

\footnotetext{
38 Entrevista 2: 28/02/2014, Barcelona.

39 Entrevista 4: 15/04/2014, Barcelona.
} 


\section{perifèria}

Número 20 (1), junio 2015

http://revistes.uab.cat/periferia

ocasionado que su relación con la administración sea burocratizada y que su "supervivencia" dependa exclusivamente de los recursos económicos que pueda obtener a través de subvenciones de administraciones públicas.

En el caso analizado, el impacto que ha tenido la reducción económica de cooperación por parte de la Generalitat, ha afectado a AlterNativa y no a su contraparte. Como consecuencia de la disminución de la financiación de la Agencia Catalana de Cooperación al Desarrollo, AlterNativa ha tenido que improvisar algunas estrategias para adaptarse a un nuevo contexto económico: la aplicación de un expediente de regulación de empleo, la búsqueda de financiación en la Unión Europea y el traslado de la sede social en un espacio compartido con otras entidades. La necesidad de obtener financiación sitúa a AlterNativa entre un discurso crítico con el sistema y una necesidad práctica de conseguir financiación para subsistir. Sin embargo, para AlterNativa, los motivos ideológicos prevalecen por encima de otras consideraciones como el acceso a ciertas fuentes de financiación que serían contradictorias con su ideología.

Por otra parte, la ausencia de financiación por parte de la Agencia Catalana de Cooperación al Desarrollo implica en la práctica una ruptura del vínculo económico entre COINDI y AlterNativa en el contexto de una relación que, de igual a igual, se caracteriza por compartir una misma ideología, a saber, el reconocimiento y pleno ejercicio de los derechos de los pueblos indígenas. Sin embargo, habría que contemplar cómo se mantiene esta relación en el tiempo ante el cese de recursos económicos.

\section{Bibliografía}

Agència Catalana de Cooperació al Desenvolupament, ACCD, ed. (2003). Pla director de cooperació al desenvolupament 2003-2006. Direcció General de Cooperació al Desenvolupament i Acció Humanitària, Agència Catalana de Cooperació al desenvolupament. Generalitat de Catalunya, Departament de la Vicepresidència.

\section{URL:http://www20.gencat.cat/portal/site/portaldogc/menuitem.c973d2fc58aa00}




\section{perifèria}

Número 20 (1), junio 2015

http://revistes.uab.cat/periferia

83e4492d92b0c0e1a0/?vgnextoid $=485946 a 6 e 5 d f e 210$ VgnVCM1000000b0c1e0aRC $\underline{\text { RD\&appInstanceName }=\text { default\&action }=\text { fit } x a \& \text { documentId }=306009 \text { \&language }=\mathrm{ca} E}$ S\&newLang=ca ES [Consulta: 30-05-2015]

(2007). Pla director de cooperació al desenvolupament 2007-2010. Direcció General de Cooperació al Desenvolupament i Acció Humanitària, Agència Catalana de Cooperació al desenvolupament. Generalitat de Catalunya, Departament de la Vicepresidència.

URL:http://cooperaciocatalana.gencat.cat/web/.content/continguts/01accd/05pla d irector/00presentacio/textcomplertpla07-10.pdf [Consulta: 30-05-2015]

AlterNativa. Intercanvi amb els pobles indígenes, ed. (s.d.). Memòria 1986-2006. 20 anys treballant per un món més just i divers. Barcelona: AlterNativa. Intercanvi amb els Pobles Indígenes, documentación cedida por la entidad. 24 pag.

(s.d). Informe final per a programes de cooperació al desenvolupament $i$ solidaritat internacional (codi convocatòria PR2008). Documentación cedida por la entidad,19 pag.

(s.d). Informe final de la convocatòria de subvencions destinades a donar suport a projectes en l'àmbit de cooperació al desenvolupament (codi de la convocatòria CD2011). Documentación cedida por la entidad, 36 pag.

Badia, Francesc et al. (2013). La cooperación descentralizada a debate. La eficacia de la ayuda y el post-2015. Barcelona: Fundació CIDOB y ART PNUD. URL:http://www.cidob.org/es/publicaciones/monografias/monografias/la_cooperaci on_descentralizada_a_debate_la_eficacia_de_la_ayuda_y_el_post_2015> [Consulta: 30-05-2015].

Bretón, Víctor (2002). "Cooperación al desarrollo, capital social y neo-indigenismo en los Andes ecuatorianos". Revista Europea de Estudios Latinoamericanos y del Caribe, n073, pp. 43-63. 


\section{perifèria}

Número 20 (1), junio 2015

http://revistes.uab.cat/periferia

Cooperación Indígena para el Desarrollo Integral, ed. (s.d). Memòria de labores 2011. URL: http://www.coindi.org/index.php/m-labores [Consulta: 30-05-2015].

El País, ed. (2013). Mas dobla el dinero para diplomacia a costa de las ONG. El País, 6 noviembre 2013.

Escobar, Arturo (1997). "Antropología y Desarrollo". Revista Internacional de Ciencias Sociales, n0154.

Escobar, Arturo (1998). La invención del Tercer Mundo. Construcción y deconstrucción del desarrollo. Bogotá: Norma.

Federació Catalana d'ONG pel Desenvolupament, FCONGD, ed. (2013). La Cooperació internacional catalana 2006-2012. Balanç d'una política pública imprescindible. Barcelona.

Gray, Andrew (2002). "Autodesarrollo: Una alternativa al 'Impasse'"en Pérez, Beatrized. (2012). Antropología y desarrollo. Discurso, prácticas y actores. Madrid: Catarata, pp.340-365.

Intermon Oxfam, ed. (2014) La realitat de l'ajuda 2013.

URL:www.oxfamintermon.org/ca/informat/publicacions/estudis/realitat-de-ajuda2014 [Consulta: 30-05-2015].

Llei 6/2011, del 27 de juliol, de pressupostos de la Generalitat de Catalunya per al 2011. Diari Oficial de la Generalitat de Catalunya, 5931, 29 juliol 2011, 4259642670. http://www15.gencat.cat/ecofin_wpres11/pdf/VOL_L_ART.pdf [Consulta: 30-05-2015]

Llei 1/2012, del 22 de febrer, de pressupostos de la Generalitat de Catalunya per al 2012. Diari Oficial de la Generalitat de Catalunya, 6075, 27 febrer 2012, 9010 9084. http://www15.gencat.cat/ecofin_wpres12/pdf/VOL_L_ART.pdf [Consulta: 3005-2015].

Llei 1/2014, del 27 de gener, de pressupostos de la Generalitat de Catalunya per al 


\section{perifèria}

Número 20 (1), junio 2015

http://revistes.uab.cat/periferia

2014.Diari Oficial de la Generalitat de Catalunya, 6551, 30 gener 2014, 1-87. http://www15.gencat.net/ecofin_wpres14/pdf/VOL_L_ART.pdf [Consulta: 30-052015].

Martínez, Monica (2010) "Una mirada antropologica a las Organizaciones no gobernamentales" en Martínez, Monica\& Larrea, Cristina. Antropología social, desarrollo y cooperación internacional: introducción a los fundamentos básicos y debates actuales. Barcelona: Editorial UOC, pp. 145-169.

Mosse, David. (2013). "The Anthropology of International Development". Annual Review of Anthropology, 42, 227-246. doi 10.1146/annurev-anthro-092412-155553 [Consulta: 30-05-2015].

Rist, Gilbert (2002). El desarrollo. Historia de una creencia occidental. Madrid: Los Libros de la Catarata.

Unceta, Koldo (2013). "Cooperación para el desarrollo: anatomía de una crisis."Íconos-Revista de Ciencias Sociales, n047, pp. 15-29.

Viola, Andreu (2014). "Discursos 'pachamamistas' versus políticas desarrollistas: el debate sobre el sumak kawsay en los Andes". Íconos. Revista de Ciencias Sociales, n047, pp. 55-72. 